\title{
UM BANCO DE DADOS ORIENTADO AO OBJETO APLICADO AO PROCESSO INDUSTRIAL DE REFRIGERAÇÃO POR AMÔNIA (NH $\left.\mathbf{N}_{3}\right)$
}

\section{A DATABASE FOR INDUSTRIAL REFRIGERATION PROCESS BY AMMONIA $\left(\mathrm{NH}_{3}\right)$}

\author{
Paulo Costa de Oliveira Filho ${ }^{1}$, Flávio Gomes de Oliveira Neto ${ }^{1}$ \\ ${ }^{1}$ Universidade Estadual do Centro-Oeste, Departamento de Engenharia Ambiental \\ e-mail: paulocostafh@gmail.com
}

Recebido para publicação em: 22/02/2010

Aceite para publicação em: 01/04/2010

\section{RESUMO}

O presente trabalho trata da implementação de um modelo de dados protótipo, visando à espacialização de um fluxograma de processo industrial de refrigeração por amônia e à sua associação a informações do banco de dados. O fluxograma de instalação frigorífica foi elaborado em um sistema CAD e adaptado e simplificado para posterior conversão para ambiente de sistema de informações georreferenciadas. Foram associados atributos inerentes aos componentes do processo e elaborados alguns exemplos aplicativos de consultas ao banco de dados e seus respectivos resultados espaciais. O sistema implementado demonstrou bons resultados em sua operacionalidade, que podem auxiliar a tomada de decisão de gestores industriais. Pode ser utilizado para o monitoramento e treinamentos nos quais é importante a visualização do lay-out ao mesmo tempo em que se consulta o banco de dados.

Palavras-Chave: Amônia. Espacialização de processo industrial. Refrigeração industrial. Sistema de informações geográficas.

\begin{abstract}
This paper discusses the implementation of a prototype data model aiming at the development of a flowchart of the industrial process of refrigeration by ammonia and its link to the database. The refrigeration installation flowchart was developed in a CAD system adapted and simplified for later conversion to a geographical information environment system. A number of inherent attributes were associated to the components of the process and some database search examples were designed along with their results. The system operation demonstrated good results that can help industry managers to make decisions.
\end{abstract}


The system can also be used in monitoring and training in which the visualization of the layout is important during the database search.

Keywords: Ammonia. Geographical distribution of industrial process. Industrial refrigeration. Geographical information system.

\section{INTRODUÇÃO}

Com o crescimento da população mundial e a demanda por produção de insumos para a sobrevivência humana, as indústrias têm aumentado sua produção, causando, consequentemente, grandes impactos ao meio ambiente. O trabalho em foco tratará da influência das indústrias que utilizam processos de resfriamento em seu ciclo produtivo.

\subsection{Processos de Refrigeração Industrial por Amônia}

Além da amônia $\left(\mathrm{NH}_{3}\right)$, os primeiros processos industriais de refrigeração utilizavam dióxido de carbono $\left(\mathrm{CO}_{2}\right)$ e dióxido de enxofre $\left(\mathrm{SO}_{2}\right)$. A partir dos anos 30, esses gases foram gradualmente substituídos com o aparecimento dos clorofluorcarbonados (CFC). O uso do CFC, entretanto, por estar fortemente associado à destruição da camada de ozônio, que culminou inclusive com o Protocolo de Montreal, em 1987, também teve que ser reavaliado, cedendo espaço a outros compostos com menor capacidade de reação com o ozônio estratosférico.

Diante desse cenário, o uso da amônia, bem menos agressiva à camada de ozônio, ganhou força nos últimos anos, principalmente em plantas industriais frigoríficas. Ainda assim, foram padronizadas e estabelecidas algumas normas de implantação e operação das instalações de amônia.

Para Vilela e Alves (2004), um agente refrigerante deve possuir no mínimo algumas das seguintes características (a maioria atendida pela amônia): ter boa capacidade de volatilização e elevado calor latente de vaporização; requerer o mínimo de potência para sua compressão à pressão de condensação; apresentar temperatura crítica bem acima da temperatura de condensação; ter pressões de evaporação e condensação razoáveis; produzir o máximo possível de refrigeração para um dado volume de vapor; ter estabilidade química; não apresentar efeito prejudi- cial sobre metais (corrosão), lubrificantes e outros materiais; não ser combustível ou explosivo nas condições de funcionamento; possibilitar que vazamentos sejam detectáveis por verificação simples; não apresentar toxicidade; ter um custo razoável em relação aos outros refrigerantes e boa disponibilidade para uso comercial.

Conforme Costa (1982), o sistema de refrigeração por amônia incide uma série de vasos e tubulações interconectados, que bombeiam e comprimem o refrigerante para um ou mais ambientes, tendo como finalidade resfriá-los ou congelá-los a uma temperatura específica. Sua complexidade varia tanto em função do tamanho dos ambientes, quanto em função das temperaturas a serem atingidas. Em se tratando de sistemas fechados, a partir do carregamento inicial, o agente refrigerante somente é adicionado ao sistema quando ocorre vazamento ou drenagem. De uma forma simplificada, podem ser percebidos três componentes distintos nos sistemas de refrigeração: o compressor, o condensador e o evaporador.

De acordo com Stoecker e Jabardo (2002), o mais importante em uma instalação frigorífica é a segurança; portanto, a eficiência do sistema deve satisfazer as premissas de segurança.

Para obter uma instalação segura, deve haver uma combinação de três fatores: projetos cuidadosos, em que as condições de segurança sejam previamente consideradas; manutenção periódica e adequada; e, finalmente, operação eficaz. A grande maioria dos acidentes com vazamentos de amônia ocorre em instalações antigas, sendo violadas várias normas de segurança.

Segundo Vilela e Alves (2004), o Brasil necessita de normas técnicas mais específicas em relação aos sistemas de refrigeração. Destacam-se as Normas Regulamentadoras do Ministério do Trabalho e Emprego, especialmente a NR-13 - Caldeiras e Vasos de Pressão, e a norma da ABNT "Vasos de pressão para refrigeração", todas de 1996. Também são utilizadas como referência as normas internacionais, conforme a Tabela 1 . 
Tabela 1 - Relação de normas relativas à segurança de instalações frigoríficas publicadas em países distintos

\begin{tabular}{c|c|c}
\hline País & Código da Norma & Título \\
\hline \multirow{2}{*}{ Brasil } & NBR 13598/1996 & Vasos de Pressão para Refrigeração \\
\cline { 2 - 3 } EUA & ANSI/ASHRAE 15/1992 & Safety Code for Mechanical Refrigeration \\
\cline { 2 - 3 } & $\begin{array}{c}\text { ASME Boiler and Pressure } \\
\text { Vessel Code, Section VIII }\end{array}$ & $\begin{array}{c}\text { Rules for Construction of Pressure Vessels, } \\
\text { Division 1, 1989. }\end{array}$ \\
\hline \multirow{2}{*}{ Inglaterra } & BS 4434 Part 1: 1989 & $\begin{array}{c}\text { Mpechanical Refrigerating Systems } \\
\text { tion Safety, General (mais 3 normas especificas } \\
\text { de mesmo código) }\end{array}$ \\
\hline Canadá & NF EN 378-2000* & $\begin{array}{c}\text { Refrigerating Systems and Heat Pumps-Safety } \\
\text { and Environmental requirements ( é constituída } \\
\text { de 4 normas especificas) }\end{array}$ \\
\hline International & ISO 5149/1993 (E) & $\begin{array}{c}\text { Mechanical Refrigeration Code } \\
\text { e aquecimentos (tradução pelo grupo de Compo- } \\
\text { nentes para Refrigeração e Condicionamento de } \\
\text { Ar, ABIMAQ, 1995) }\end{array}$ \\
\hline
\end{tabular}

indústria, considerando áreas internas, lay-outs de produção, ou toda a logística de produção e escoamento, há como aplicar tal ferramenta para que haja facilidades nos mecanismos de geração de plantas inteligentes ou plantas temáticas adequadas a determinadas necessidades.

Talvez algumas aplicações não sejam tão comuns devido à falta de conhecimento da existência da disponibilidade da tecnologia. Essa é uma ferramenta que tem sido mais utilizada quando as áreas de trabalho são grandes regiões delimitadas por coordenadas geográficas. Contudo, a tecnologia de banco de dados espacial pode ser muito útil se aplicada ao contexto de uma planta de processo industrial, como no caso em questão.
*NF - Norma Francesa (ANFOR); EM - Norma Europeia Fonte: Stoecker e Jabardo, (2002)

\subsection{Sistemas de Informações Geográficas ou Banco de Dados Espaciais}

Os sistemas de informações geográficas (SIGs) ou banco de dados espaciais são usualmente aceitos como uma tecnologia necessária para realizar análises com dados espaciais (SILVA, 1999).

Esses sistemas oferecem alternativas de visualização de resultados de análises e dados espaciais que podem beneficiar a tomada de decisão. Conforme Maguirre et al (1991), um SIG pode ser definido a partir de três propriedades: a capacidade de apresentação cartográfica de informações complexas, uma base integrada de objetos espaciais e de seus atributos ou dados, e um conjunto de procedimentos e ferramentas de análise espacial.

Ferrari (1997), entre outros, defende a implementação de sistemas de informações geográficas específicos para determinadas aplicações. $\mathrm{Na}$ atualidade, diversas são as aplicações que têm feito parte do vasto campo em que atuam os sistemas de informações geográficos ou georreferenciados. $\mathrm{Na}$

\subsection{Softwares Livres}

Nos últimos anos foram desenvolvidos vários aplicativos de domínio público para as mais variadas aplicações. O SPRING é um SIG no estado-da-arte com funções de processamento de imagens, análise espacial, modelagem numérica de terreno e consulta a bancos de dados espaciais (SPRING, 1996). O SPRING é um projeto do INPE - Instituto Nacional de Pesquisas Espaciais que tem a participação de instituições de pesquisa, empresas e universidades, entre as quais a EMBRAPA/CNPTIA, IBM do Brasil, TECGRAF/PUC-RIO, PETROBRÁS/CENPES e CNPq.

O presente trabalho teve como objetivo a implementação de um modelo de dados orientado ao objeto, utilizando um software de domínio público, para espacializar um fluxograma de tubulação industrial que abrange vários fatores intervenientes ao sistema de refrigeração industrial de amônia, incluindo equipamentos específicos para recalque, transporte e acondicionamento do fluido refrigerante. Essa não é uma aplicação convencional, mas se pretende, com o uso de sistemas orientados a objetos, um meio de monitorar grandes fluxogramas industriais quanto a variações nos dados relacionados aos equipamentos 
e tubulações, referentes à troca e substituição de equipamentos, parâmetros que devam ser monitorados constantemente na indústria, ou mesmo como simples informação e suporte para treinamentos e tomada de decisão.

\section{MATERIAIS E MÉTODOS}

Para a realização do trabalho, foram verificadas as características dos equipamentos frigoríficos e sua finalidade no sistema, sendo utilizado um fluxograma adaptado de uma indústria de embutidos. Em ambiente CAD, realizou-se uma síntese do fluxograma, com a vetorização das linhas e adequação topológica, sendo posteriormente exportada para o sistema de informações georreferenciadas - SIG SPRING, versão 5.1.3. No SIG, foi implementado um modelo de dados orientado a objetos ou entidades gráficas poligonais, onde essas entidades representam os equipamentos do sistema, tais como válvulas, compressores, evaporadores, condensadores evaporativos, recipiente de amônia e separadores de liquido. Já o modelo de dados é formado por uma série de atributos que são diretamente associados aos componentes "equipamentos do sistema". Devido à maior complexidade dos desenhos e detalhes de simbologias de equipamentos e de projetos elaborados em sistema CAD, cada equipamento teve uma adaptação em sua representação vetorial, para que houvesse possibilidade de atender à aplicação de banco de dados orientado a objetos.
Para a definição da área de abrangência do projeto no modelo de dados do SPRING (retângulo envolvente) foram admitidas e transportadas as coordenadas cartesianas do ambiente CAD. O sistema implementado está relacionado com uma indústria frigorífica de produção de embutidos, empreendimento no qual a refrigeração industrial por amônia é bastante utilizada. A figura 1 representa um fluxograma básico de produção de salsicha e de mortadela. O processo de refrigeração está inserido nesse tipo de indústria, desde a recepção da matéria-prima até a expedição do produto final.
Figura 01 - Fluxograma Básico de Produção de Embutidos.

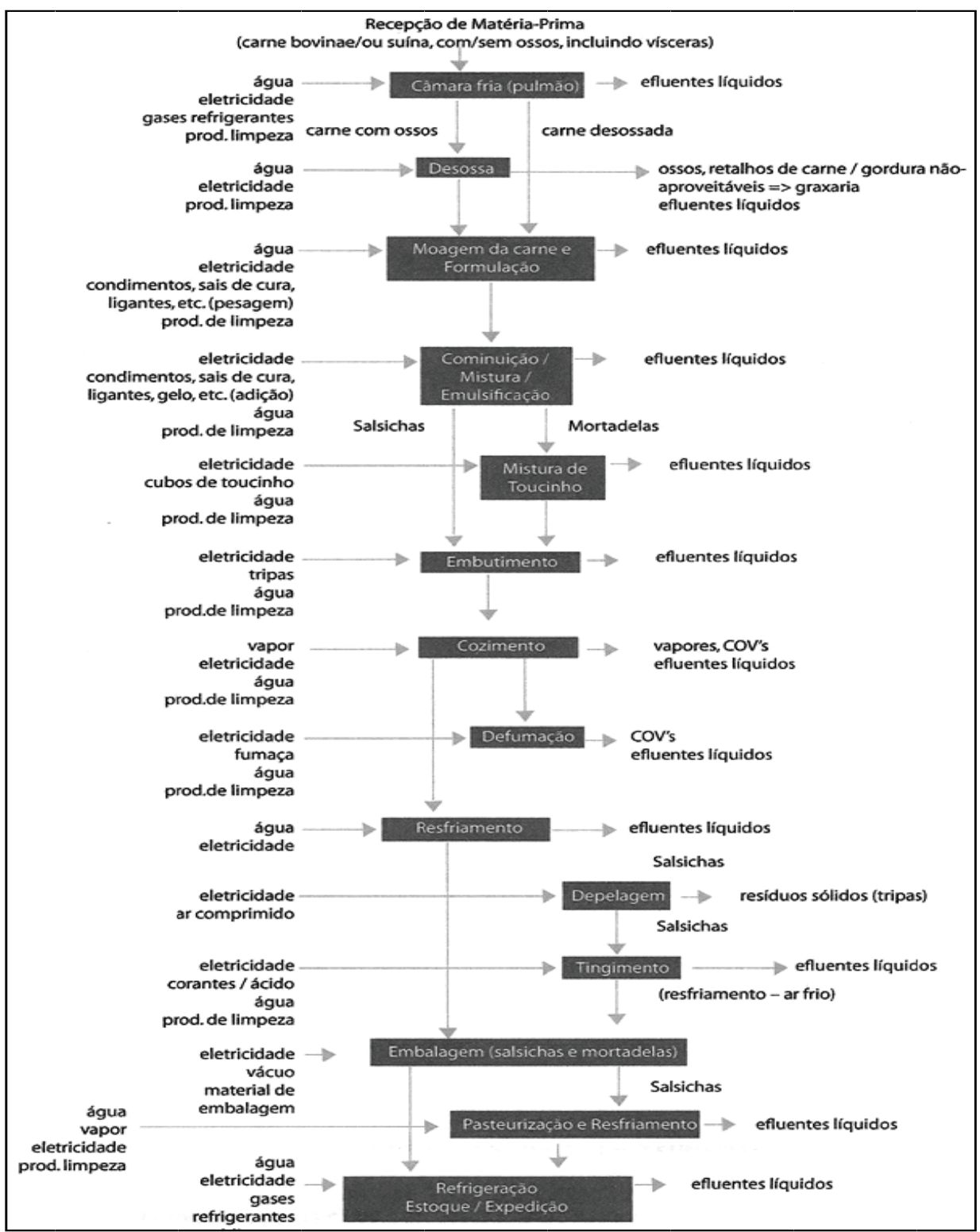

Fonte: RIMEF Refrigeração Industrial Ltda. 
Figura 02 - Fluxograma de Refrigeração Industrial de Amônia.

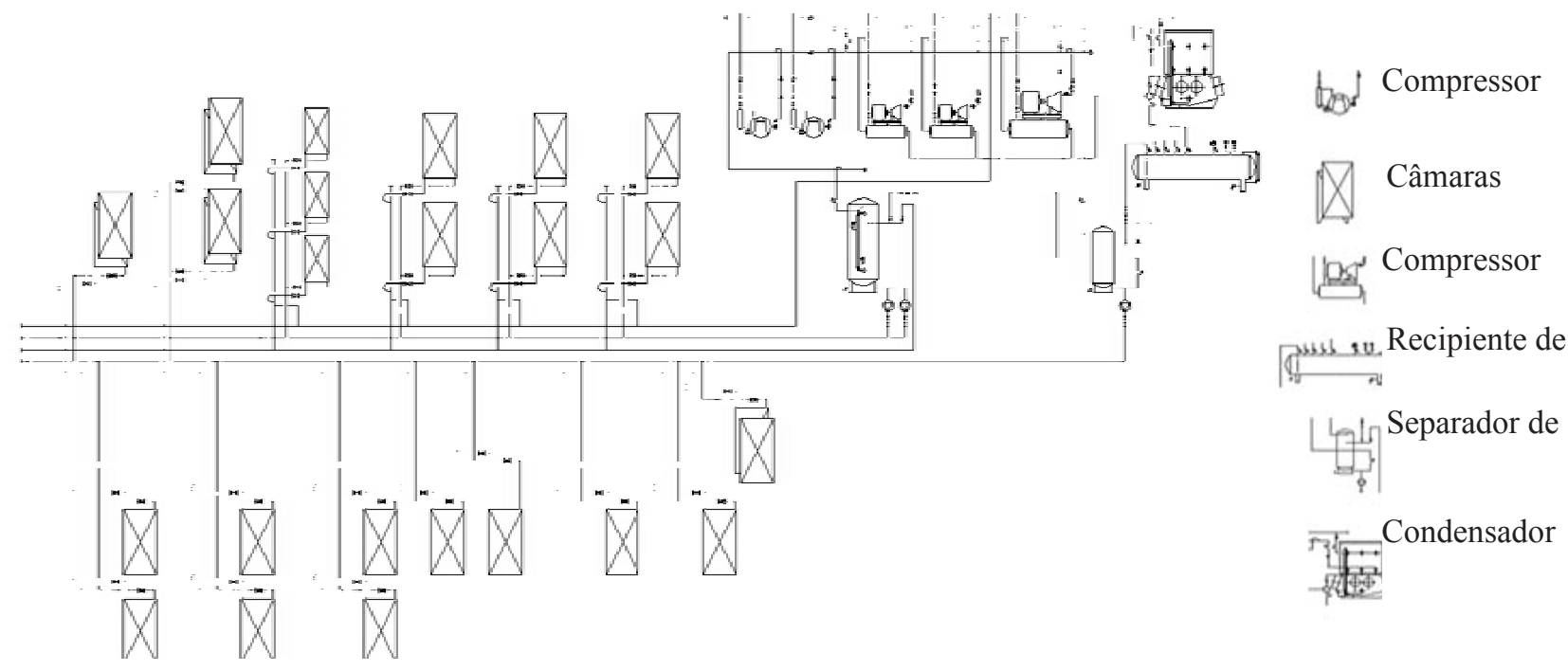

Fonte: RIMEF Refrigeração Industrial Ltda.

\subsection{Descrição dos Componentes do Sistema}

Os componentes do sistema de refrigeração industrial para a produção de embutidos foram detalhados a seguir, de acordo com Dossat (1987). $\mathrm{O}$ quadro 02 descreve e ilustra detalhadamente os equipamentos do sistema frigorífico.

Quadro 2 - Descrição detalhada e ilustrada dos equipamentos frigoríficos

Recipiente de Líquido: vaso de pressão com finalidade de armazenar amônia condensada, sendo dimensionado para suprir possíveis oscilações de fluxo e nível de líquido, conforme o sistema. Instalado na parte externa da sala de máquinas, por segurança, em local arejado e com ventilação abundante, abaixo do nível das tubulações, em posição vertical, é composto por chapas de aço calandradas e soldadas, pressão de teste de $24 \mathrm{Kgf} / \mathrm{cm}^{2}$. Com conexões para entrada e saída de liquido, gás quente e dreno de ar, e domo de impureza, sua dimensão é definida de acordo com a necessidade do sistema frigorífico.

Condensador Evaporativo: o gás a ser condensado circula através da serpentina de condensação, a qual é resfriada constantemente com água recirculada. O ar forçado pelo ventilador causa a evaporação de uma pequena quantidade de água. Essa evaporação retira calor da serpentina, resfriando-a com consequente condensação do gás. São fabricados em diversos modelos com capacidade nominal que varia de $55.000 \mathrm{Kcal} / \mathrm{h}$ até $2.616 .000 \mathrm{Kcal} / \mathrm{h}$.

Compressores Alternativos: conhecidos como recíprocos ou de pistão, operam com fluidos bastante específicos e em condições de sucção e descarga pouco variáveis. São compressores volumétricos que conseguem a elevar a pressão através da redução do volume de uma câmara (cilindro) ocupada pelo gás.

Compressor Parafuso: possui dois rotores em forma de parafusos que giram em sentido contrario, mantendo entre si uma condição de engrenamento. $\mathrm{O}$ gás penetra pela abertura de sucção e ocupa os intervalos entre os filetes dos rotores. A rotação faz com que o ponto de engrenamento vá se deslocando para frente, reduzindo o espaço disponível para o gás e provocando a sua compressão. Finalmente é alcançada a abertura de descarga, e o gás é liberado.
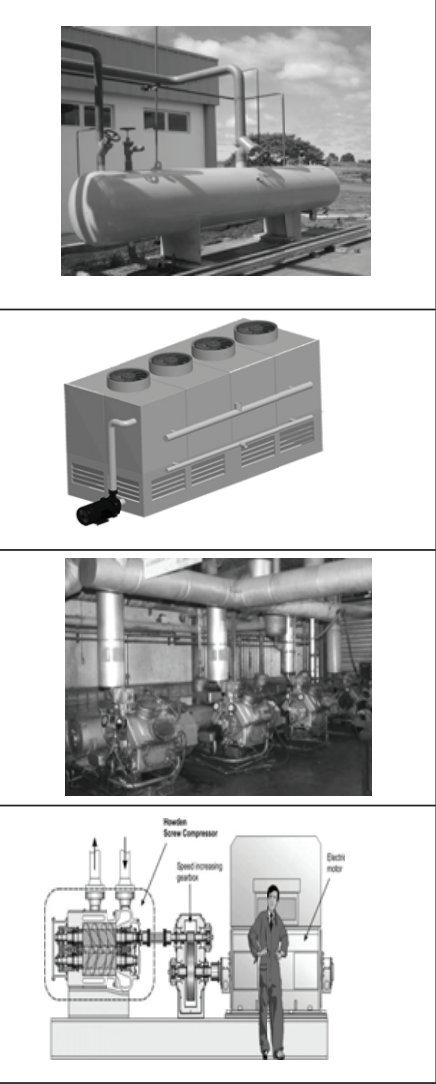

continua 
continuação

\begin{tabular}{|c|c|}
\hline $\begin{array}{l}\text { Evaporador: responsável pela absorção de calor para o sistema de refrigeração, } \\
\text { ele recebe a amônia líquida (refrigerante frio), de baixa pressão, vaporiza-o em seu } \\
\text { interior, constituído por um tubo com placas finas de metal fixadas entre os tubos. } \\
\text { As aletas melhoram a eficiência da transferência de calor, devido a aumentarem a } \\
\text { área global de troca de calor. Responsável pela circulação, resfriamento e também } \\
\text { congelamento do setor da indústria. }\end{array}$ & AL alofimenTO DO EVAPORADOR \\
\hline $\begin{array}{l}\text { Separador de Líquido: a finalidade dos separadores de líquido no sistema é a de } \\
\text { garantir o fluxo de vapor em uma determinada linha, normalmente após evapo- } \\
\text { radores inundados. Os separadores de circulação forçada utilizam bombas para } \\
\text { circular o refrigerante líquido entre o separador e o evaporador. Podemos notar em } \\
\text { instalações frigoríficas a utilização de separadores verticais e horizontais. }\end{array}$ & \\
\hline
\end{tabular}

Fonte: DOSSAT, 1987.

conclusão

A seguir, serão detalhados outros componentes do sistema, conforme Silva Telles (2001):

Tubulações: são condutores fechados, destinados principalmente ao transporte de fluidos. Todos os tubos são de seção circular, apresentando-se como cilíndricos ocos. A grande maioria dos tubos funciona como condutos forçados, isto é, sem superfície livre, com o fluido tomando toda a área da secção transversal. Na refrigeração industrial utilizam-se tubos de aço carbono, por se tratar de um material que apresenta menor relação custo/resistência mecânica, alem de ser um material fácil de soldar e de ser encontrado no comércio. Emprega-se aço carbono desde água doce, vapor de baixa pressão, condensado, ar comprimido, óleos, gases e muitos outros fluidos pouco corrosivos, em temperaturas desde - 45 graus Celsius, e a qualquer pressão. Alguns fatores que devem ser considerados quando projetado um sistema de refrigeração industrial: a conexão da linha de descarga dos compressores no coletor principal da descarga deve ser feita com inclinação máxima de 45 graus; as válvulas de serviços localizadas na saída dos condensadores devem estar instaladas na direção do fluxo num nível de $300 \mathrm{~mm}$ abaixo da conexão de saída dos condensadores. Outro detalhe importante a ser considerado é o subdimensionamento nas linhas de refrigeração, que pode provocar os seguintes problemas:

- Linha de descarga: aumenta a pressão de descarga e, consequentemente, o consumo de potência, mas a consequência operacional mais séria é o aumento da temperatura de descarga, a qual provoca um maior arraste de óleo.

- Linha de sucção: provoca a diminuição da pressão de sucção, o aumento do volume específico do vapor da sucção e a diminuição da capacidade efetiva do compressor. Principalmente em baixas temperaturas, pequenas perdas de pressão podem significar perdas sensíveis de capacidade.

- Linha de líquido: pode provocar a evaporação do líquido antes das válvulas de expansão, o que reduz sensivelmente a capacidade da válvula, reduzindo também a capacidade efetiva do sistema.

Válvulas e controles: são dispositivos destinados a estabelecer, controlar e interromper o fluxo em uma tubulação. São os acessórios mais importantes existentes nas tubulações, e por isso devem merecer o maior cuidado na sua seleção, especificação e localização.

Válvulas de bloqueio: são as válvulas que se destinam apenas a estabelecer ou interromper o fluxo, isto é, que só devem funcionar completamente abertas ou completamente fechadas.

Válvula de passagem reta: válvulas reguladoras de pressão na saída de evaporadores, possuem funções muito importantes no sistema, tais como manter uma pressão constante dentro de evaporador, evitar problemas de congelamento, arraste de líquido excessivo, sob pressão. As válvulas e controles de evaporadores devem estar localizados fora da câmara frigorífica, facilitando a manutenção e evitando a contaminação do produto em caso de vazamento em algum desses componentes.

Com base no fluxograma das instalações do sistema (figura 1), que aborda a característica dos equipamentos frigoríficos, tubulações e válvulas, foi implementado um banco de dados georreferenciado, associado a cada componente do processo produtivo, o qual possibilitou realizar agrupamentos de 
geo-objetos por atributo e consultas por expressão lógica.

\section{RESULTADOS E DISCUSSÃO}

A figura 3 exibe a planta com a distribuição dos equipamentos frigoríficos dentro dos setores de refrigeração industrial, obtida por agrupamento dos objetos "equipamentos" por setor de produção. Da mesma forma, foram obtidas as seguintes plantas temáticas: Planta de Equipamentos (figura 4), Planta de Consumo de Energia (figura 5), Planta de Modelo dos Equipamentos (figura 6), Planta de Risco de Vazamento de Amônia (figura 7), Planta de Potência dos Equipamentos (figura 8) e Planta de Regime de Temperatura (figura 9).

Figura 3 - Planta de Setores da Indústria.

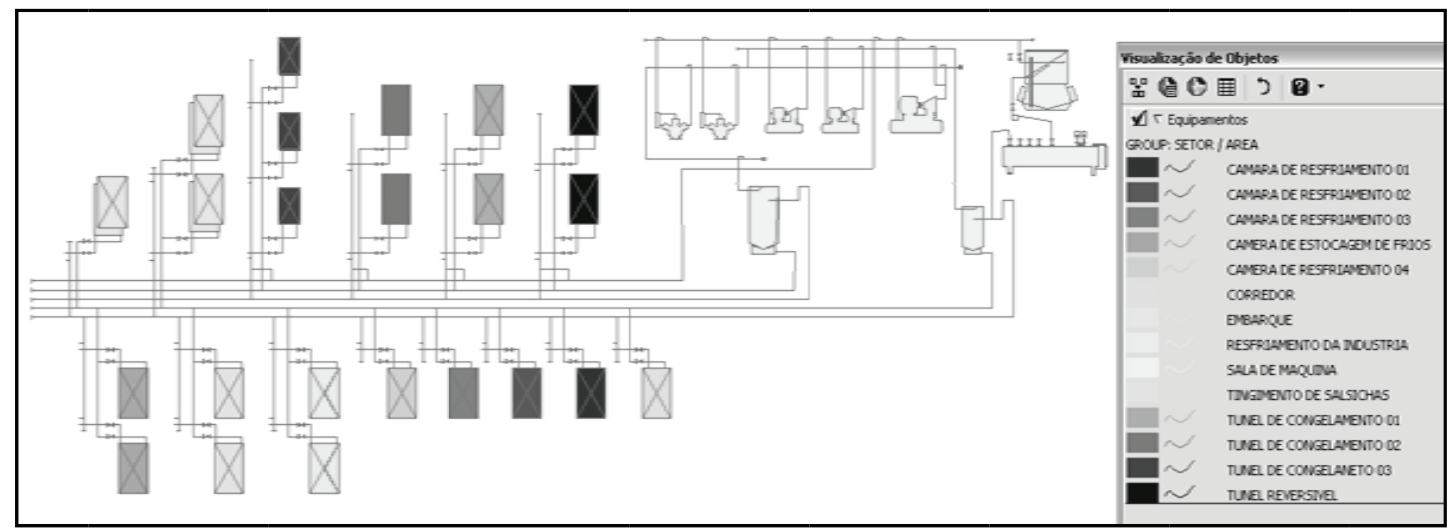

Figura 4 - Planta de Equipamentos Frigoríficos.

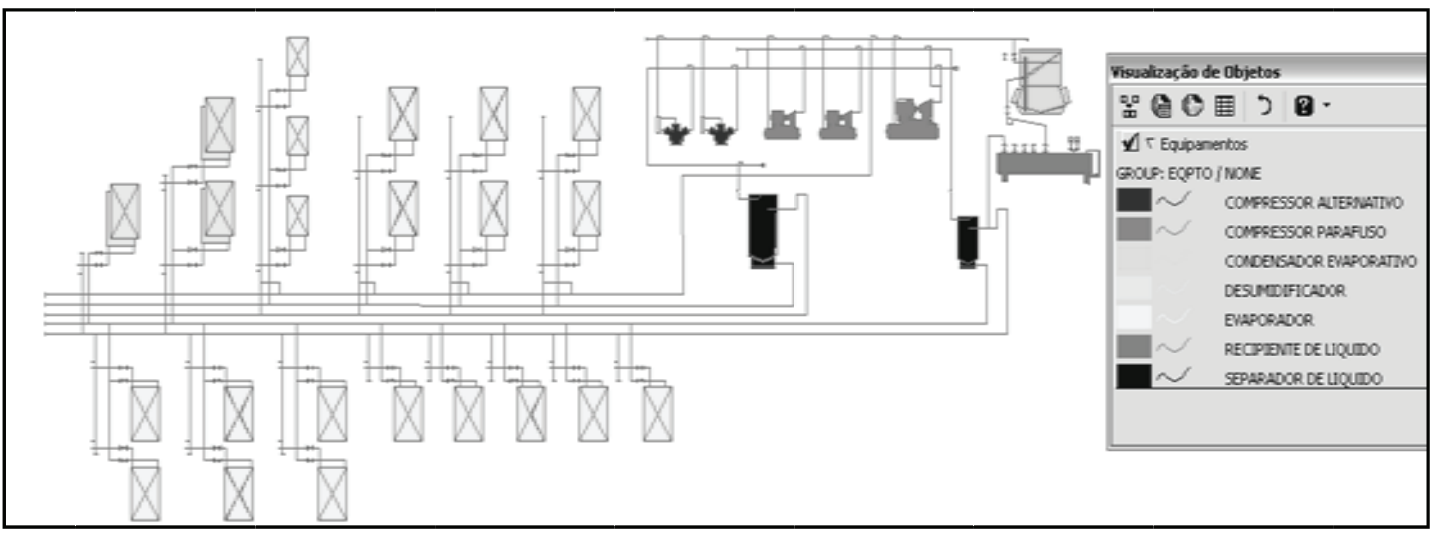

Figura 5 - Planta de Consumo de Energia em Wats.

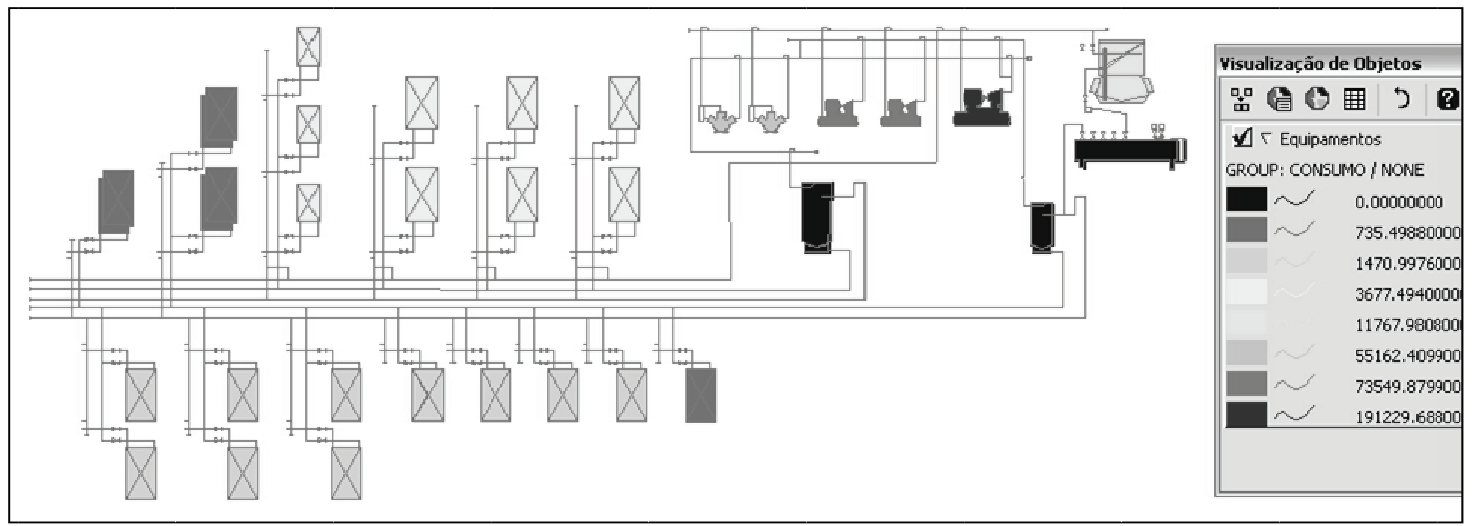


Figura 6 - Planta de Modelo dos Equipamentos.

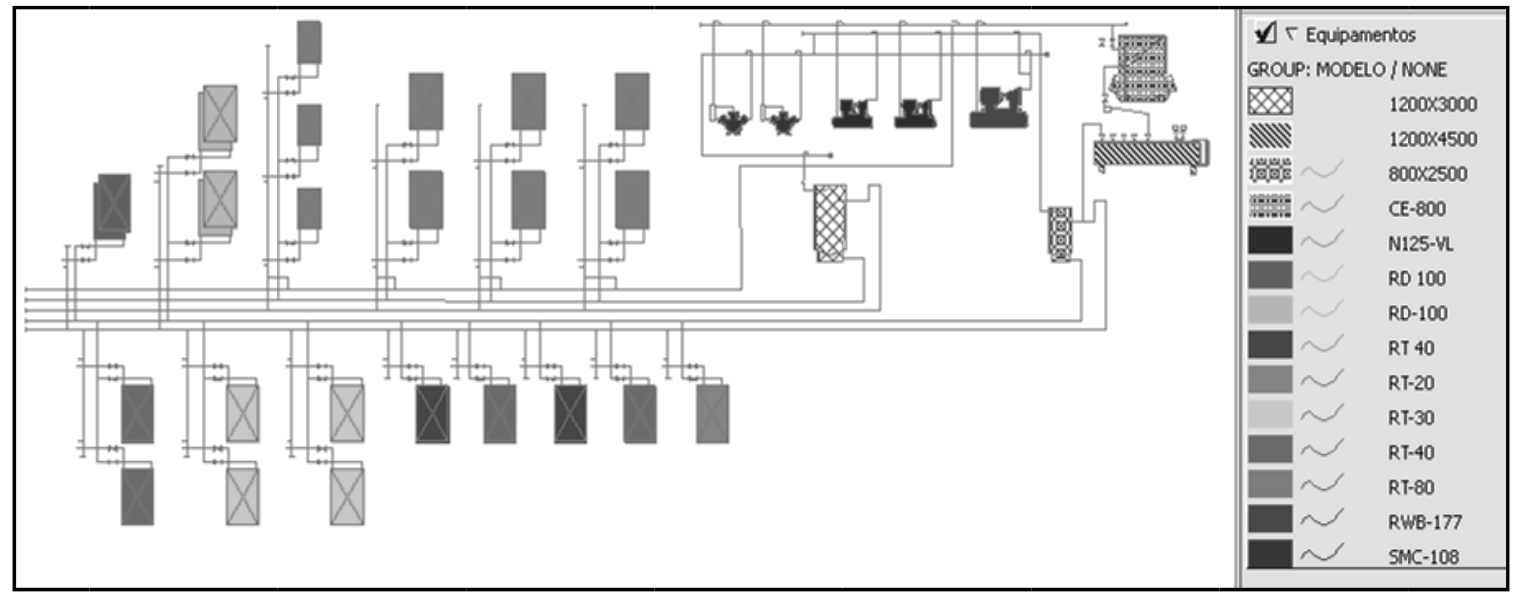

Figura 7 - Planta de Risco de Vazamento de Amônia.

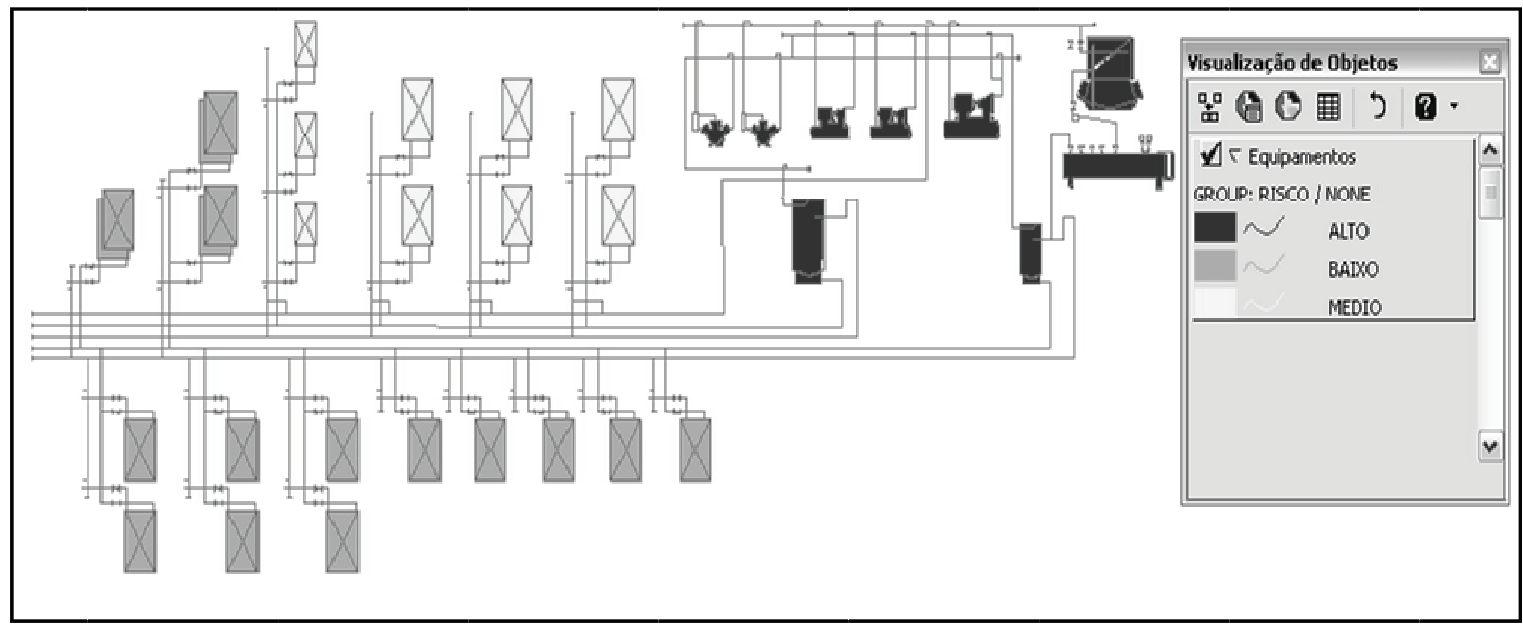

Figura 8 - Planta de Potência dos Equipamentos em Cavalo-Vapor.

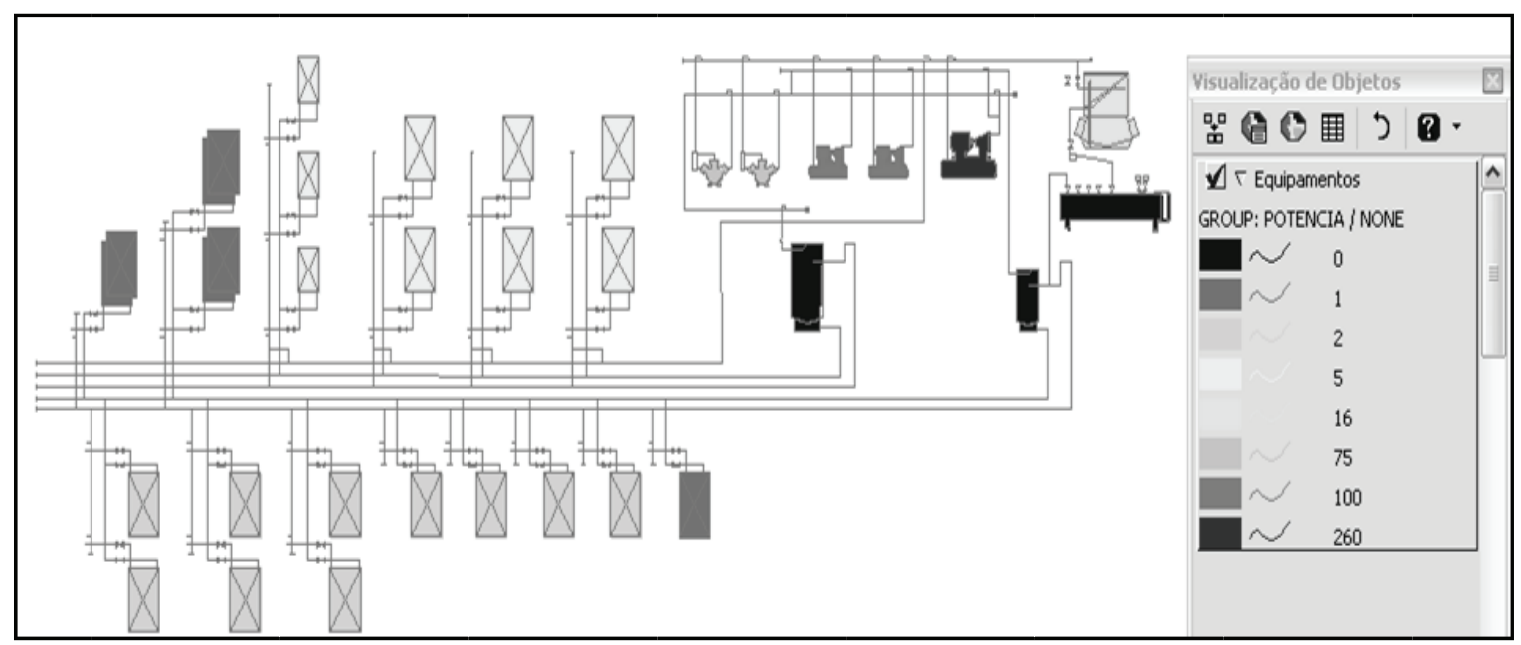


Figura 9 - Planta de Regime de Temperatura em Graus Celsius.

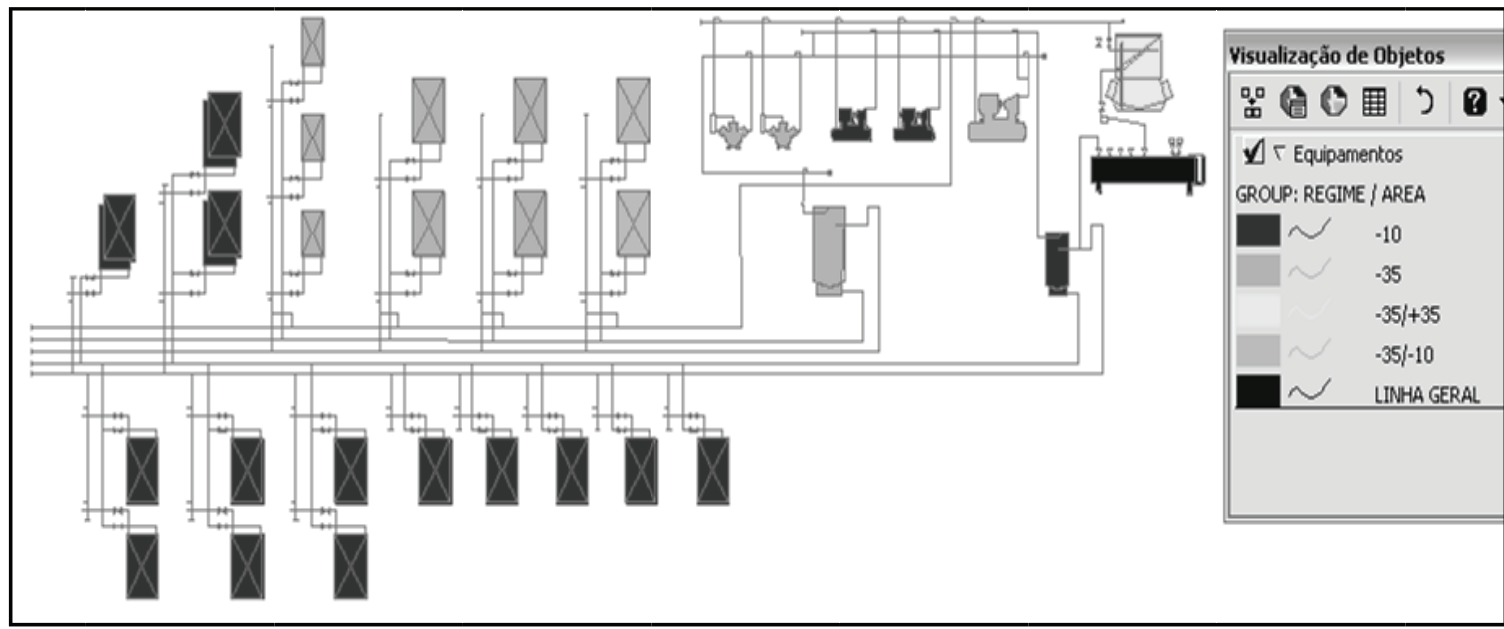

Outra função aplicada no modelo de dados foi a consulta de seleção de objetos por expressão lógica. O módulo de consulta por atributos pode fornecer a planta com as restrições definidas na expressão. A interface de consulta utiliza dois operadores lógicos, .AND. e .OR., e os seguintes operadores de comparação: $=$ igualdade; $<>$ diferença; < menor que; $>$ maior que; $<=$ menor ou igual a; e $>=$ maior ou igual a.

Nessa ferramenta, quanto maior o número de atributos e maior a complexidade do banco de dados, maior será o poder de consulta. A figura 10 apresenta uma consulta que seleciona os equipamentos em função do consumo e do alto risco de vazamento de amônia. As expressões utilizadas nas consultas serão indicadas da seguinte forma: Expressão Lógica e respectiva descrição da consulta.

Consulta 01

CG000010- $>$ CONSUMO $>=\mathbf{5 0 0 0 0}$.AND.

(seleciona os equipamentos com consumo igual ou superior a $50000 \mathrm{Watts} / \mathrm{h}$ e)

CG000010->RISCO = 'ALTO'

(que tenha alto risco de vazamento de amônia)

Figura 10 - Seleção de equipamentos por consumo e risco de vazamento.

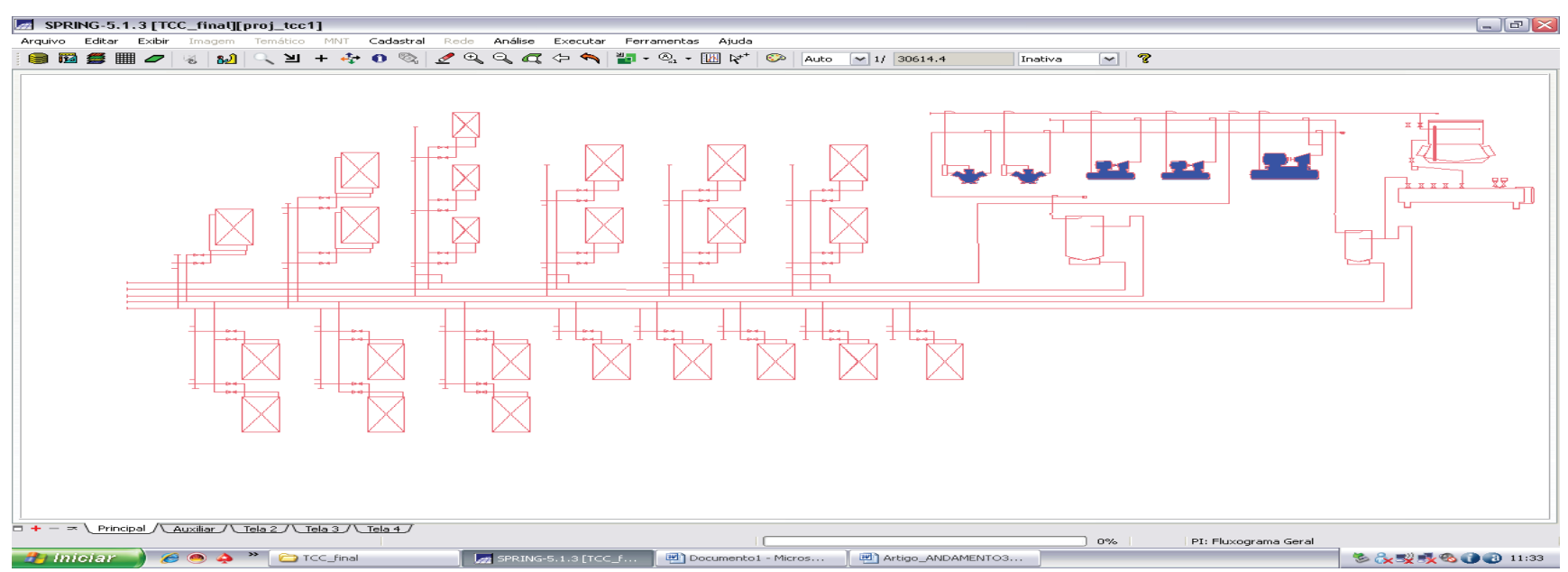

A figura 11 apresenta a consulta que seleciona os equipamentos com um determinado regime de trabalho em função da temperatura em graus Celsius.
Consulta 02

CG000010- $>$ REGIME $=\mathbf{~} \mathbf{-} \mathbf{3 5} / \mathbf{- 1 0}$ '

(seleciona os equipamentos cujo regime é $-35 /-10)$ 
Figura 11 - Seleção de equipamentos conforme o regime de trabalho em função da temperatura em graus Celsius.

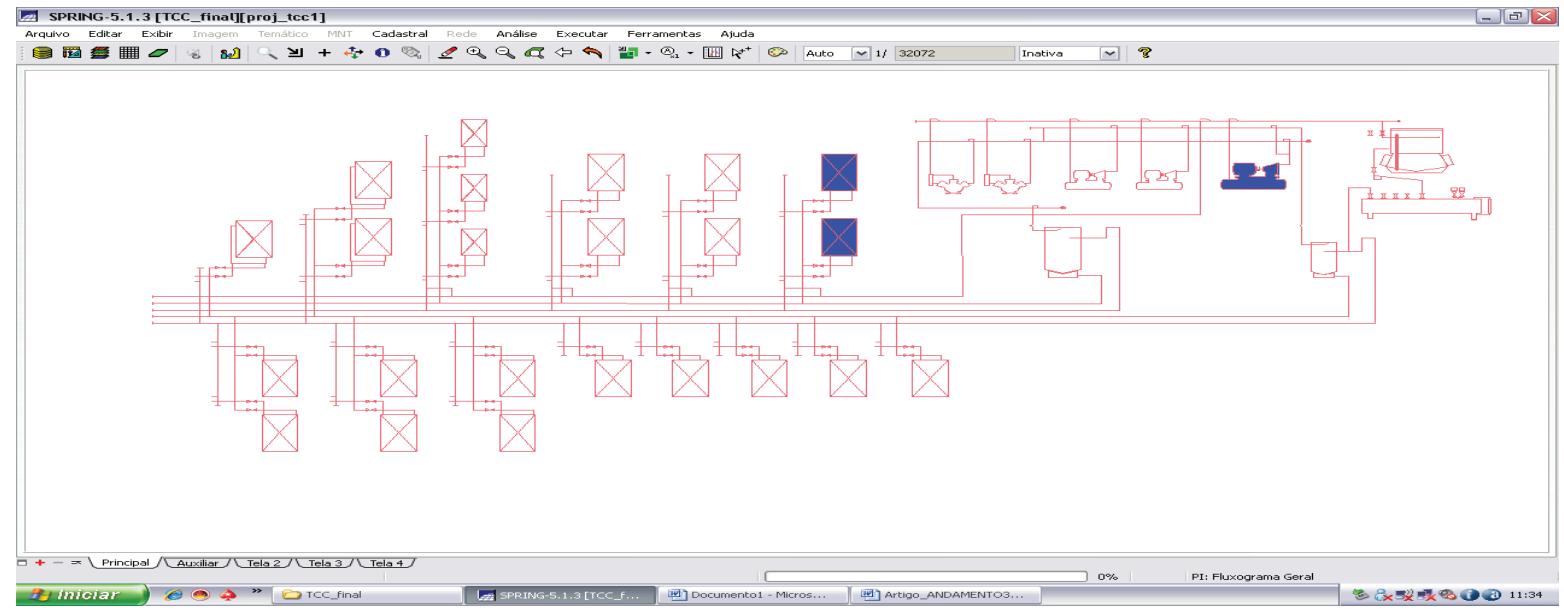

A aplicação ora apresentada pode monitorar a expansão da indústria, seu consumo de energia, a divisão de setores e seus diferentes equipamentos, seus modelos, os regimes de trabalho e suas ligações, a potência, a capacidade, o risco de vazamento de amônia, entre outros. É possível utilizar esse modelo de dados também para elaborar lay-outs ou saídas gráficas temáticas conforme o assunto que se queira abordar dentro das questões inerentes ao processo industrial, de tal maneira que, sendo constantemente alimentado, o sistema sempre apresentará resultados atuais gráficos e de consulta. Essas saídas gráficas podem dar apoio a algum treinamento, podendo ser utilizadas como auxílio ou para formar painéis de instrução para estagiários ou visitantes. Além disso, o banco de dados interligado aos equipamentos componentes do sistema pode proporcionar rápidas consultas que, apresentando o resultado conjugado teórico-espacial, trazem um nível de informação adicional que pode ser fundamental na tomada de decisão.

Durante a execução do trabalho, foram observadas algumas dificuldades no momento de conversão dos dados para o SIG. A conversão de formatos gráficos ou vetoriais, devido aos arquivos do CAD serem mais complexos quanto à quantidade de linhas (entidades de representação gráfica), tornou mais intenso o trabalho de edição topológica. Mesmo assim, as adaptações foram realizadas em CAD com certa facilidade, para que depois os arquivos fossem novamente transportados e importados de forma correta pelo aplicativo do tipo SIG. Os sistemas CAD - Computer Aided Design, normalmente utilizados para realizar projetos gráficos, possuem muitos recursos nesse campo, o que quase sempre resulta em projetos, desenhos ou fluxogramas bastante complexos.

Quando as representações gráficas a serem importadas pelos aplicativos do tipo SIG possuem certo grau de complexidade, normalmente são encontradas dificuldades de importação por esses sistemas, onde as aplicações em geral não exigem desenhos muito complexos. Isso ocorre porque a grande maioria das ferramentas dos aplicativos SIG é de análise e não de desenho. Dessa forma, quando o objetivo do trabalho confronta um projeto como um fluxograma industrial e um aplicativo de ambiente de sistema de informações geográficas, podem ocorrer dificuldades para se obter uma representação adequada em CAD, e que o SIG reconheça sem problemas. Entre essas dificuldades, pode-se citar a quebra de entidades gráficas ou objetos em diversas partes, a superposição de linhas, erros de codificação em níveis e atributos, detalhamento excessivo com simbologias ou hachuras associadas a linhas, excesso de vértices, erros de fechamentos topológicos, desencontros de bordas e também textos gráficos divididos em varias partes.

No presente estudo as dificuldades encontradas ocorreram principalmente devido ao detalhamento excessivo de simbologias e hachuras. Após detectado o problema, foi realizada uma edição vetorial e a adequação do modelo topológico do fluxograma industrial. A adequação foi operacionalizada com a elaboração de uma síntese do fluxograma original, bem mais simples, sem, contudo, perder suas peculiaridades técnicas. Dessa forma, encontrou-se a 
solução para satisfazer às necessidades topológicas do modelo. O quadro 03 mostra alguns detalhes da simplificação da representação gráfica de equipamentos utilizados no fluxograma original e a respectiva síntese.

Quadro 03 - Descrição detalhada e ilustrada de alguns equipamentos

Alternativo antes
da simplificação

de decisão de gestores industriais, trazendo facilidades no monitoramento da expansão da indústria, seu consumo de energia, a divisão de setores e seus diferentes equipamentos, seus modelos, os regimes de trabalho e suas ligações, a potência, a capacidade, o risco de vazamento de amônia, entre outros.

- O sistema implementado também pode, desde que sempre atualizado, gerar lay-outs industriais com diferentes temáticas, de acordo com os atributos do banco de dados alfanumérico, para cursos, treinamentos e orientação aos visitantes.
De uma forma geral, o modelo de dados implementado proporcionou a visualização espacial de resultados que podem auxiliar a tomada de decisão para gestores industriais. Algumas aplicações, tais como a elaboração de painéis indicativos para treinamentos e visitantes, fazem da manutenção de um banco de dados espacial atualizado uma importante estratégia de controle e de fácil visualização de dados, abrangendo uma grande amplitude de temas.

\section{CONCLUSÃO}

- Conforme o sistema implementado, verificou-se que na conversão de arquivos vetoriais sem sistema de referência conhecida, elaborados em ambiente CAD e transportadas para ambiente SIG, é necessário considerar as coordenadas cartesianas originais do sistema CAD.

- A espacialização de projetos industriais exige uma adaptação e/ou simplificação dos fluxogramas, transformando-os em sínteses para a adaptação topológica necessária no modelo de dados espacial.

- A edição gráfica de projetos industriais pode apresentar maiores facilidades se executada em ambiente $\mathrm{CAD}$, devido à complexidade dos desenhos (projetos) e à disponibilidade de ferramentas desses aplicativos.

- O protótipo implementado demonstrou bons resultados em sua operacionalidade, obtendo resultados que podem auxiliar o planejamento e a tomada

\section{AGRADECIMENTOS}

Os autores agradecem a Antônio Sampaio, Técnico em Refrigeração Industrial por Amônia, da Empresa RIMEF Refrigeração Industrial Ltda, pelo fornecimento dos dados utilizados neste trabalho.

\section{REFERÊNCIAS}

COSTA, E. C. Refrigeração. São Paulo: Edgard Blücher, 1982. 134p.

DOSSAT, Roy. Princípios de Refrigeração. São Paulo: Ed. Hemus, 1987. 231p.

FERRARI, R. Viagem ao SIG: planejamento estratégico, viabilização, implantação e gerenciamento de sistemas de informação geográfica. Curitiba: Sagres, 1997. 174p.

MAGUIRRE, D.J., GOODCHILD, N.S., RHIND, D.W. Geographical Informations Systems: Principals and Aplications. Longman, London, 1991. 224p.

SILVA, A.B. Sistemas de informações geo-referenciadas: conceitos e fundamentos. Campinas: Unicamp, 1999. 236p.

SILVA TELLES, P.C. Tubulações industriais: materiais, projeto, montagem. 10a . edição, Livros Técnicos e Científicos Editora S.A. Rio de Janeiro, 2001.

SPRING: Integrating remote sensing and GIS by objectoriented data modelling" Camara G, Souza RCM, Freitas UM, Garrido J Computers \& Graphics, 20: (3) 395-403, May-Jun 1996. 
STOECKER, W. F.; JABARDO, J. M. S. Refrigeração Industrial. São Paulo: Editora Edgard Blücher Ltda, 2002. $384 \mathrm{p}$.

VILELA, R.U.B.V.; ALVES, V.C.R. Refrigeração Industrial por Amônia: riscos, segurança e auditoria fiscal. Brasília: MTE, SIT, DSST, 2004. 31p. Disponível em: $<$ http://www.mte.gov.br/seg_sau/pub_cne_refrigeracao. pdf $>$. Acesso em: 22 março. 2010. 